\title{
Responsiveness of dairy research in generating improved dairy practices in West Shewa zone of Oromia, Ethiopia
}

\author{
WORKNEH ABEBE WODAJO, K. PONNUSAMY AND SUDHANAND PRASAD LAL
}

\begin{abstract}
Dairy research has been undertaking since 1960s in Ethiopia. However, the majority of the farmers still continue to adopt traditional dairy practices. This study was made to look into the current status of dairy research in generating responsive improved dairy practices. To achieve the objective of the study, cross sectional survey was employed using 50 researchers in the area of livestock sector. A systematic sampling technique was employed to identify the sample respondents. Holistically, to capture all the relevant information, mixed methods such as focus group discussion, key informant interview, questionnaire and observation were used for data collection. The data were analyzed using descriptive statistics, content analysis and ranking. The study clearly indicated that the improved dairy practices generation process of the study area was less responsive mainly due to lack of clear dairy research strategy. Evidently, low dairy productivity and low level use of improved dairy practices are the key indicators. Likewise, inadequate laboratory equipments, inadequate laboratory facility (building) and inadequate budget support were the central constraints of the dairy research in order of their importance. Generally, in the dairy research efforts of several decades, the numbers of generated, disseminated and adopted improved dairy practices were not worth mentioning. It necessitates formulation of dairy research strategy that leads to the generation of responsive improved dairy practices which, in turn, brings significant impact on the dairy development.
\end{abstract}

KEY WORDS : Dairy research, Improved dairy practices, Livestock, Responsive

HOW TO CITE THIS PAPER : Wodajo, Workneh Abebe, Ponnusamy, K. and Lal, Sudhanand Prasad (2016). Responsiveness of dairy research in generating improved dairy practices in West Shewa zone of Oromia, Ethiopia. Res. J. Animal Hus. \& Dairy Sci., 7(1) : 39-46 : DOI: 10.15740/ HAS/RJAHDS/7.1/39-46.

\footnotetext{
Address for correspondence :

Workneh Abebe Wodajo, Department of Rural Development and Agricultural Extension, Ambo University, AMBO, ETHIOPIA

Email : wawj2017@gmail.com

Associated Authors':

K. Ponnusamy and Sudhanand Prasad Lal, National Dairy Research Institute, KARNAL (HARYANA) INDIA

Email : ponnusamyk@hotmail.com ; sudhanandlal100@gmail.com
} 